\title{
Pembuatan Aneka Masakan dari Bahan Lele
}

\author{
Making Various Dishes from Catfish
}

\author{
Catur Rini Sulistyaningsih \\ Fakultas Pertanian, Universitas Veteran Bangun Nusantara Sukoharjo \\ caturrinisulistyaningsih@gmail.com
}

Riwayat Artikel: Dikirim 28 September 2018; Diterima 28 Mei 2019; Diterbitkan 31 Mei 2019

\begin{abstract}
Abstrak
Pengabdian Kepada Masyarakat ini adalah untuk meningkatkan kemampuan dan keterampilan serta pendapatan kepada para anggota PKBM Desa Pondok Kecamatan Nguter Kabupaten Sukoharjo. Tentang pembuatan aneka masakan dari bahan lele yang berfariasi dan bernilai gizi tinggi. Kegiatan ini dimulai dengan mengadakan sosialisasi kepada paran anggota, karena di desa ini banyak dijumpai masyarakat yang membudidayakan lele. Pelaksanaanh penyeluruhan diawali dengan memberikan penyuluhan dalam bentuk ceramah dan diskusi, dilanjutkan pelatihan dan pendampingan pembuatan aneka ragam masakan dari bahan lele. Kemudian dilakukan evaluasi bagi peserta untuk mengetahui keberhasilan kegiatan dengan mengadakan kegiatan pre test maupun post test. Hasil pre test menunjukkan bahwa sebelum pelatihan dimulai peserta masih kurang faham tentang tentang materi dengan rerata nilai 1,482. Setelah melaksanakan pelatihan rerata nilai pos test terhadapat pemahaman, peserta mengalami peningkatan 92,325\% ini menunjukkan bahwa kegiatan pengabdian kepada masyarakat berhasil meningkat pengetahuan dan keterampilan serta dapat menambah penghasilan peserta mengelola lele menjadi aneka masakan yang lezat dan bergizi tinggi.
\end{abstract}

Kata kunci: lele, aneka masakan

\begin{abstract}
This Community Service is to improve the abilities and skills and income of the members of the PKBM Pondok Nguter District, Sukoharjo Regency. This is about making various dishes from catfish ingredients that vary and have high nutritional value. This activity was started by holding socialization to the members, because in this village there were many people who cultivated catfish. The dissemination began with giving counseling in the form of lectures and discussions, followed by training and mentoring to produce a variety of dishes made from catfish. Then an evaluation is carried out for participants to find out the success of the activity by holding pretest and post-test activities. The pre-test results showed that before the training began the participants still did not understand about the material with a mean value of 1,482. After carrying out the average training on the value of the postal test for understanding, participants experienced an increase of $92.325 \%$ indicating that community service activities were successful in increasing their knowledge and skills and could increase the income of participants in managing catfish into delicious and highly nutritious dishes.
\end{abstract}

Keywords: catfish, various dishes

\section{PENDAHULUAN}

Desa Pondok, Kecamatan Nguter, Kabupaten Sukoharjo, merupakan salah satu desa yang sebagian besar warganya bermata pencaharian dalam budidaya ikan lele. Luas wilayah Desa Pondok \pm 253.397 $\mathrm{Ha}$ dan tinggi daratan $\pm 200 \mathrm{~m}$ diatas permukaan laut. Kondisi semacam ini sangat bagus untuk membudidayakan ikan lele.
Desa pondok ini sudah terkenal oleh masyarakat sekitar sebagai sentra ikan lele di wilayah Sukoharjo. Dimana ada beberapa proses dalam budidaya lele yang dilakukan antara lain pemijihan, pembesaran, olahan pakan lele, olahan pasca panen dan pemasaran.

Desa Pondok Kecamatan Nguter Kabupaten Sukoharjo ini sudah menjadi "Desa Vokasi" karena desa tersebut sudah memiliki PKBM (Persatuan Kegiatan 
Bersama Masyarakat). Salah satu kegiatan yang diselenggarakan di PKBM tersebut adalah dalam hal budidaya lele, dimana dikenal dengan nama "Ulam Sari Makmur" dengan anggota 20 pembudidayakan lele. Selain itu, di Desa Pondok para pembudidaya lele juga sudah memiliki suatu perkumpulan/ paguyuban para peternak lele, dimana di dalam paguyuban tersebut para peternak saling bertukar pikiran atau berdiskusi tentang usaha budidaya lelenya, apabila ada masalah dalam budidaya lele biasanya diselesaikan bersama.

Selain itu, sumber daya yang ada di Desa Pondok dapat dimanfaatkan untuk menunjang kemajuan budidaya lele, dan masyarakat mempunyai keinginan dan mendukung untuk memajukan usaha budidaya lele dengan menyediakan sarana dan prasarana yang layak dipergunakan bagi warga Desa Pondok. Saranan dan prasarana dalam membudidayakan lele di Desa Pondok ini, baik kondisi jalan dan kondisi sarana yang lain juga sudah cukup memadai.

Nama ikan lele sudah tidak asing lagi bagi kita semua, yang sangat digemari oleh semua kalangan karena dagingnya yang sangat gurih dan lezat. Tidak jarang hampir semua restoran atau di warung-warung menyediakan menu lele. Selain dagingnya yang gurih, ikan lele mempunyai keunggulan tak bersisik dan bisa hidup lebih lama sehingga mempermdah proses pengolahan. Pada daging lele juga terdapat banyak kandungan gizinya.

Dengan banyaknya kandungan gizi yang terdapat di dalam daging lele, maka masyarakat banyak yang mengkonsumsi ikan lele. Oleh karena itu, Tim Pengabdian berusaha untuk membuat inovasi produk olahan lele sehingga masyarakat tetap bisa mengkonsumsi ikan lele namun dalam bentuk produk yang berbeda. Dalam kegiatan Pengabdian ini akan menjadi mitra justru adalah ibu-ibu PKK di Desa Pondok, dengan alasan bahwa para pembudidaya lele berfokus pada usaha budidaya lele, sedangkan para ibu-ibu hanya sekedar membantu, dan memang pada dasarnya para ibu-ibu pasti memiliki hobi memasak. Selain itu, dengan inovasi produk olahan leli ini, diharapkan ibu-ibu PKK Desa Pondok memiliki suatu usaha dengan memanfaatkan potensi lokal yang dimilikinya, sehingga mengangkat nilai jual lele dalam bentuk olahan dan meningkatkan pendapatan bagi ibu-ibu PKK di Desa Pondok Kecamatan Nguter Kabupaten Sukoharjo.

Desa Pondok Kecamatan Nguter Kabupaten Sukoharjo merupakan desa sentral budidaya lele. Biasanya lele yang dihasilkan hanya dijual dalam bentuk mentah saja. Terdapat para ibu-ibu yang berprofesi sebagai ibu rumah tangga, dimana mereka memiliki hobi memasak yang sebenarnya bisa dikembangkan. Dengan adanya potensi ikan lele di Desa Pondok maka Tim Pengabdian akan melakukukan kegiatan pengabdian dalam upaya memmanfaatkan potensi lokal yang dimiliki dengan memberikan penyeuluhan dan pelatihan inovasi produk olahan lele kepada para ibu-ibu PKK Desa Pondok agar ikan lele memiliki nilai tambah dan bernilai tinggi sehingga menambah pendapatan.

\section{METODE PELAKSANAAN}

Solusi yang di tawarkan sesuai dengan permasalahan prioritas yang disepakati dengan PKBM pada gambar 1 .

Gambar 1.

Solusi yang disepakati dengan PKBM

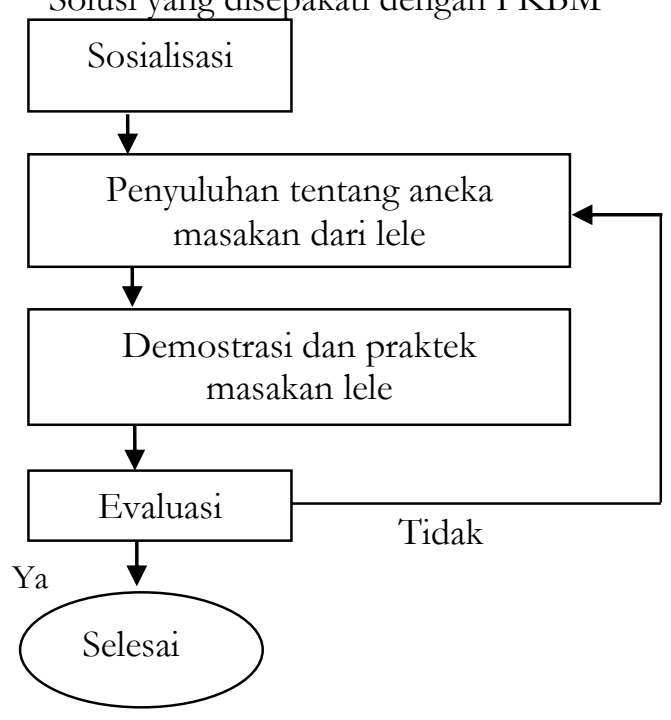


Dari gambar 1 tampak bahwa PKBM (Persatuan Kegiatan Bersama Masyarakat) Desa Pondok Kecamatan Nguter yang beranggotaan 80 mempunyai masalah yang harus segera diselesaikan (1) sebagian besar atau $80 \%$ dari jumlah anggota belum mengetahui cara memanfaatkan sumber daya alam yang ada (lele). (2) belum memahami perhitungan secara ekonomi dalam hubungannya dengan pembuatan macam macam olahan lele dan belum mengetahui bahwa olahan bermacam-macam lele dapat meningkatkan pendapatan. Alternatif pemecahan masalah yaitu ngan mengadakan peyuluhan dan pelatihan mengenai aneka masakan dari bahan lele serta perhitungan secara ekonominya.

Kemudian dilakukan evaluasi bagi peserta untuk mengetahui keberhasilan dari kegiatan. Dengan mengadakan pre test. Jika 'ya' berarti kegiatan yang dilakukan berhasil meningkatkan pengetahuan dan ketrampilan anggota PKBM Desa Pondok Kecamatan Nguter dalam mengelola lele menjadi aneka masakan yang lezat dan bergizi, tetapi jika 'tidak' berarti kegiatan penyuluhan dan praktek mengolah lele harus diulangi lagi.

\section{HASIL DAN PEMBAHASAN}

\section{Hasil}

Kegiatan pengabdian kepada masyarakat dengan cara memberikan penyuluhan dan pelatihan tentang pengolahan aneka masakan dari bahan lele di PKBM Desa Pondok Kecamatan Nguter, Kabupaten Sukoharjo ditunjukan untuk peningkatan pengetahuan dan keterampilan warga belajar tentang pengolahan aneka masakan dari bahan lele agar bernilai ekonomi tinggi.

Tabel 2.

Rerata nilai tingkat pemahaman peserta penyuluhan dan pelatihan pengolahan aneka masakan dari bahan lele.

\begin{tabular}{|l|c|c|c|}
\hline \multirow{2}{*}{ Butir } & \multicolumn{3}{|c|}{ Rerata Tingkat Pemahaman } \\
\cline { 2 - 4 } & $\begin{array}{c}\text { Sebelum } \\
\text { kegiatan }\end{array}$ & $\begin{array}{c}\text { Sesudah } \\
\text { kegiatan }\end{array}$ & $\begin{array}{c}\text { Presentase } \\
\text { peningkatan }\end{array}$ \\
\hline $\begin{array}{l}\text { Penyuluhan dan pelatihan } \\
\text { pengolahan aneka masakan dari } \\
\text { bahan lele }\end{array}$ & 1.482 & 2.85026 & 92.325 \\
\hline
\end{tabular}

Catatan :

skor 1 : tidak tahu

skor $2 \quad$ : sedikit tahu

skor $3 \quad$ : tahu

skor $4 \quad$ : sangat tahu

Hasil pre test menunjukkan bahwa sebelum pelatihan dimulai peserta masih kurang paham tentang materi dengan rerata nilai 1.482. Setelah melaksanakan pelatihan rerata nilai post test 2.85026 ini berarti pemahaman peserta terhadap materi yang diberikan mengalami peningkatan $92.325 \%$. Hal ini menunjukkanbahwa kegiatan pengabdian kepada masyarakat berhasil meningkat pengetahuan dan keterampilan peserta dalam mengolah aneka resep masakan dari bahan lele. Dan ternyata dari hasil pengamatan pelatihan pembuatan bakso lele, nugget lele dan krupuk lele.

\section{Pembahasan}

Keberhasilan ini tidak lepas dari adanya dukungan warga masyarakat PKBM, Desa Pondok, Kecamatan Nguter, Kabupaten Sukoharjo terhadap pelaksanaan ini, selain itu keingintahuan warga masyarakat PKBM Desa Pondok, Kecamatan Nguter, Kabupaten Sukoharjo tentang pengolahan lele menjadi aneka masakan lezat dan bergizi sangat besar. 
Pengetahuan tentang aneka masakan dari lele belum pernah diterima warga masyarakat PKBM Desa Pondok, Kecamatan Nguter, Kabupaten Sukoharjo sehingga mereka antusias sekali dalam mengikuti kegiatan pelatihan. Di desa Pondok dan sekitarnya bahan baku lele mudah diperoleh dan harganya pun relatif murah.

Faktor penghambat dari kegiatan ini relatif kecil, karena pendidikannya sejajar dan ternyata adanya pembimbingan/arahan untuk wirausaha sehingga peserta merespon. Hanya untuk berikutnya perlu adanya pengetahuan tindak lanjut tentang marketingnya.

\section{KESIMPULAN}

Kegiatan pengabdian kepada masyarakat di PKBM Desa Pondok Kecamatan Nguter Kabupaten Sukoharjo melalui penyuluhan dan pelatihan aneka resep masakan dari lele, dapat meningkatkan pengetahuan dan keterampilan warga masyarakat PKBM Desa Pondok, Kecamatan Nguter, Kabupaten Sukoharjo sebesar 92,325\% maka perlu ada keberlanjutan program dan pendampingan bagi peserta kegiatan yang dinilai mampu mensosialisasikan dan menyebarluaskan kegiatan ini ke PKBM serta dukungan dari berbagai pihak yang kondusif terhadap kemajuan kegiatan perekonomian.

\section{DAFTAR PUSTAKA}

Anomim. (1981). Daftar Komposisi Bahan Makanan. Bharata Karya Aksara Jakarta.

Krisnawan, Andre. (2012). Sukses Beternak Lele Dumbo dan Lele Lokal. Pustaka Baru Press. Yogyakarta. 